\title{
Postpartum mental illness during the COVID-19 pandemic: a population-based, repeated cross- sectional study
}

\author{
Simone N. Vigod MD, Hilary K. Brown PhD, Anjie Huang MSc, Kinwah Fung MSc, Lucy C. Barker MD, \\ Neesha Hussain-Shamsy MSc, Elisabeth Wright MD, Cindy-Lee Dennis PhD, Sophie Grigoriadis MD, \\ Peter Gozdyra MA, Daniel Corsi PhD, Mark Walker MD, Rahim Moineddin PhD
}

Cite as: CMAJ 2021 June 7;193:E835-43. doi: 10.1503/cmaj.210151

\begin{abstract}
BACKGROUND: It is unclear whether the clinical burden of postpartum mental illness has increased during the COVID-19 pandemic. We sought to compare physician visit rates for postpartum mental illness in Ontario, Canada, during the pandemic with rates expected based on prepandemic patterns.
\end{abstract}

METHODS: In this population-based, repeated cross-sectional study using linked health administrative databases in Ontario, Canada, we used negative binomial regression to model expected visit rates per 1000 postpartum people for March-November 2020 based on prepandemic data (January 2016February 2020). We compared observed visit rates to expected visit rates for each month of the pandemic period, generating absolute rate differences, incidence rate ratios (IRRs) and their 95\% confidence intervals (Cls). The primary outcome was a visit to a primary care physician or a psychiatrist for any mental disorder. We stratified analyses by maternal sociodemographic characteristics.

RESULTS: In March 2020, the visit rate was $43.5 / 1000$, with a rate difference of $3.11 / 1000$ (95\% Cl 1.25-4.89) and an IRR of 1.08 (95\% Cl 1.03-1.13) compared with the expected rate. In April, the rate difference $(10.9 / 1000,95 \% \mathrm{Cl}$ 9.14-12.6) and IRR (1.30, 95\% Cl 1.24-1.36) were higher; this level was generally sustained through November 2020. From April-November, we observed elevated visit rates across provider types and for diagnoses of anxiety, depressive and alcohol or substance use disorders. Observed increases from expected visit rates were greater for people 0-90 days postpartum compared with 91-365 days postpartum; increases were small among people living in low-income neighbourhoods. Public health units in the northern areas of the province did not see sustained elevations in visit rates after July; southern health units had elevated rates through to November.

INTERPRETATION: Increased visits for mental health conditions among postpartum people during the first 9 months of the COVID-19 pandemic suggest an increased need for effective and accessible mental health care for this population as the pandemic progresses.
P

ostpartum mental illness affects as many as 1 in 5 mothers, ${ }^{1}$ and can result in maternal suffering and diminished functioning. ${ }^{2}$ Related impaired mother-infant interactions are linked to poor social, cognitive and behavioural outcomes in children across their lifespan. ${ }^{3}$ When mental illness becomes chronic and recurrent, its effects can extend to the entire family and across generations. ${ }^{4}$ With emergence of the novel coronavirus (SARSCoV-2), the World Health Organization declared a global COVID-19 pandemic on Mar. 11, 2020. Globally, efforts to contain the virus have led to widespread travel restrictions, physical distancing and work limitations, causing broad social and financial disruption that has been associated with substantial mental health effects. ${ }^{5,6}$
During the COVID-19 pandemic, people have been reporting concerns about postpartum infection, ${ }^{7}$ and difficulty accessing the extended postpartum social support networks and key community programs that protect against mental illness, such as home visits from public health nurses, breastfeeding clinics and support groups, owing to public health measures. ${ }^{8}$ In Canadian surveys, about $50 \%$ of pregnant people reported psychological distress in spring 2020, ${ }^{9}$ and alcohol use increased among women, particularly among those with young children. ${ }^{10}$ Whether this represents an increased clinical burden of mental illness or need for care is unknown.

Using routinely collected health care data from Ontario, Canada, (population of about 14.6 million), we aimed to examine 
whether rates of maternal visits to physicians for postpartum mental illness from March to November 2020 differed from expected visit rates based on pre-COVID-19 patterns, and to identify variation by provider type, clinical diagnosis, postpartum timing, parity, income, ethnicity and region of residence.

\section{Methods}

\section{Study design and data sources}

We designed a population-based, repeated cross-sectional study using deidentified patient-level records that were linked using a unique encoded identifier. We used Ontario's Registered Persons Database, which captures sex, age, postal code and dates of birth for all Ontario residents. We also used ICES' MOMBABY data set, derived from the Canadian Institutes of Health Information's Discharge Abstract Database, which provides health records for all in-hospital births in Ontario (> 98\% of births). ${ }^{11}$ We used the Ontario Health Insurance Plan Database, which captures billing claims for all physician services rendered, including mental health visits, along with the clinical diagnoses assigned by the providers. ${ }^{12}$ Data on in-hospital births were fully reported to Sept. 30, 2020, with more than $90 \%$ of health regions reporting up to Nov. 30, 2020 at the time of analysis. Complete data on billing claims were available up to Nov. 30, 2020, for the analysis.

\section{Time period and participants}

The World Health Organization declared a global pandemic on Mar. 11, 2020, and a state of emergency was declared in Ontario on Mar. 17, 2020. ${ }^{13}$ We used data from January 2016 to February 2020 to establish baseline, prepandemic visit rates and data from March-November 2020 to measure visit rates during the pandemic. At-risk postpartum time started on the date of a live birth delivery and ended on the 365th day after delivery, a standard time frame used for diagnosis of postpartum mental disorders in research and clinical practice. ${ }^{14}$ We assessed at-risk time daily to allow an individual to contribute days-at-risk to each monthly tally. Individuals with invalid or missing encoded identifiers did not contribute days-at-risk, as their data could not be linked across data sets to measure visit rates. If an individual had a second eligible delivery within 1 year of the first, the at-risk time restarted on the date of the second delivery.

For each person contributing at-risk time, we collected the following data from time of delivery: maternal age; parity (primiparous, multiparous) from the MOMBABY data set; neighbourhood income quintile, using postal code information linked with Census income data; South Asian or Chinese ethnicity, Canada's 2 largest visible minority populations, based on surname (specificity $>99.5 \%$; sensitivity $50 \%$ for people of South Asian descent and $80 \%$ for those of Chinese descent because people with last names not unique to those populations are not categorized into one of the groups); $;^{15}$ neighbourhood ethnic diversity quintile (i.e., the proportion of individuals who are visible minorities or new immigrants within a neighbourhood, using the Ontario Marginalization Index); ${ }^{16}$ and region of residence according to the province's 34 public health units, which we grouped into northern $(n=7)$ and southern $(n=26)$ public health units. ${ }^{17}$

\section{Outcomes}

The primary outcome was an outpatient physician visit for mental illness to a primary care provider or to a psychiatrist, derived from physician billing claims ${ }^{18}$ (Appendix 1, Table S1, available at www. cmaj.ca/lookup/doi/10.1503/cmaj.210151/tab-related-content). We defined visits as either in-person or virtual, inclusive of telephone and video visits, measured by existing physician billing codes and those that were newly introduced during the pandemic. We categorized clinical diagnoses using the 3-digit diagnostic code that is recorded during the visit for billing purposes by the provider based on the International Classification of Diseases, 8th Revision, including anxiety and related disorders (300), depressive or other nonpsychotic disorders not elsewhere classified (311), bipolar disorders (296), psychotic disorders $(295,297,298)$ and alcohol or substance use disorders $(303,304)$. We classified remaining mental illness codes as "other disorders" (Appendix 1, Table S1). Neither comorbid nor secondary diagnoses are recorded using this system.

\section{Statistical analysis}

Using data from January 2016 to February 2020, we used negative binomial regression to model prepandemic monthly visit rates/1000 postpartum people, with prepandemic time and month of the year as predictors. We used the log of the number of postpartum people in each month as an offset. We modelled residuals as an autoregressive $\mathrm{AR}(1)$ process to account for serial correlation among the residuals and to account for seasonality. We then used the fitted model to predict the expected visit rate for each month from March through November 2020, using the number of postpartum people in these months as the offset variables.

For the primary analysis, we calculated the absolute rate difference (95\% confidence interval $[\mathrm{Cl}]$ ) between the observed and expected visit rate for each month from March to November 2020 by subtracting the observed rate from the expected rate. We also calculated the incidence rate ratio (IRR, 95\% CI) of the observed versus expected rate by dividing the observed rate by the expected. We repeated analyses by provider type and clinical diagnosis.

In secondary analyses, we stratified the analysis of the primary outcome by time since delivery (0-90 d, the highest risk time for mental disorders during the postpartum period, ${ }^{19} \mathrm{v} .91-365 \mathrm{~d}$ ) and by sociodemographic characteristics at time of delivery, including maternal parity, neighbourhood income quintile, surname-based ethnicity group (Chinese, South Asian, other), neighbourhood ethnic diversity quintile and region of residence (northern or southern public health unit). We analyzed data using SAS 9.4 for Unix.

\section{Ethics approval}

Data use was authorized under section 45 of Ontario's Personal Health Information Protection Act, so we did not require ethics board approval for this study.

\section{Results}

A median of 137609 eligible postpartum people contributed at-risk time monthly from March to November 2020, of which a median of $30 \%$ (range $29.0 \%-31.4 \%$ ) were $0-90$ days postpartum. Mean maternal age at delivery across the 9 months was 31.3 (standard 
deviation 0.03 ) years. A median of $44.0 \%$ (range $43.5 \%-44.5 \%$ ) were primiparous, and a median of $21.5 \%$ (range $21.4 \%-21.5 \%$ ) lived in a neighbourhood of the lowest income quintile. A median of 5.3\% (range 5.1\%-5.4\%) and 5.3\% (range 5.0\%-5.4\%) were classified as having Chinese and South Asian surnames, respectively, and a median of $33.1 \%$ (range $32.9 \%-33.2 \%$ ) lived in a neighbourhood of the most ethnically diverse quintile. A median of $5.1 \%$ (range 5.1\%-5.2\%) lived in a northern public health unit.
Prepandemic, a mean of $3.1 \%$ of postpartum people had at least 1 visit for mental illness during any given month, and about $3.1 \%$ of these visits were conducted virtually. During the pandemic, a mean of $3.6 \%$ of postpartum people had at least 1 visit in any given month (Table 1). In March 2020, 46.3\% of visits were virtual, increasing to $84.8 \%$ in April, and decreasing slightly over time to $72.4 \%$ in November. Although $80.3 \%$ of mental health visits to primary care providers were virtual in April, this decreased

Table 1: Observed and expected rates, absolute rate differences and rate ratios of mental health visits for postpartum people in Ontario from March to November 2020

\begin{tabular}{|c|c|c|c|c|c|c|c|c|}
\hline Month & $\begin{array}{l}\text { No. of eligible } \\
\text { postpartum } \\
\text { people }\end{array}$ & $\begin{array}{l}\text { No. of } \\
\text { postpartum } \\
\text { people with a } \\
\text { visit (\% of } \\
\text { eligible people) }\end{array}$ & $\begin{array}{l}\text { No. of } \\
\text { visits }\end{array}$ & $\begin{array}{l}\text { No. of } \\
\text { virtual visits } \\
\text { (\% of visits) }\end{array}$ & $\begin{array}{r}\text { Rate } / 1000 \\
\text { pe }\end{array}$ & $\begin{array}{l}\text { ostpartum } \\
\text { ple }\end{array}$ & $\begin{array}{l}\text { Absolute rate } \\
\text { difference } \\
(95 \% \mathrm{Cl})\end{array}$ & $\begin{array}{c}\text { Incidence rate } \\
\text { ratio } \\
(95 \% \mathrm{Cl})\end{array}$ \\
\hline \multicolumn{9}{|l|}{ Overall } \\
\hline March & 137766 & $4714(3.4)$ & 6000 & 2778 (46.3) & 43.6 & 40.4 & 3.1 (1.2 to 4.9$)$ & 1.08 (1.03 to 1.13 ) \\
\hline April & 137467 & $4928(3.6)$ & 6973 & $5910(84.8)$ & 50.7 & 38.9 & 11.7 (10.0 to 13.5$)$ & $1.30(1.24$ to 1.36$)$ \\
\hline May & 137867 & $4761(3.5)$ & 6616 & $5438(82.2)$ & 48.0 & 41.2 & 6.7 (4.8 to 8.6$)$ & 1.16 (1.11 to 1.22$)$ \\
\hline June & 137707 & $5058(3.7)$ & 7034 & $5533(78.7)$ & 51.1 & 39.1 & $12.0(10.2$ to 13.7$)$ & $1.31(1.25$ to 1.37$)$ \\
\hline July & 138238 & $5058(3.7)$ & 6823 & $5094(74.7)$ & 49.4 & 36.7 & 12.6 (10.9 to 14.2 ) & 1.34 (1.28 to 1.41$)$ \\
\hline August & 137609 & $4721(3.4)$ & 6196 & $4531(73.1)$ & 45.0 & 37.9 & 7.1 (5.4 to 8.8$)$ & $1.19(1.14$ to 1.24$)$ \\
\hline September & 136820 & $5026(3.7)$ & 6762 & $4957(73.3)$ & 49.4 & 38.6 & $10.8(9.0$ to 12.5$)$ & $1.28(1.22$ to 1.34$)$ \\
\hline Octobert & 135377 & $5016(3.7)$ & 6732 & $4926(73.2)$ & 49.7 & 40.8 & 9.0 (7.1 to 10.8$)$ & 1.22 (1.17 to 1.28$)$ \\
\hline November† & 133241 & $4999(3.8)$ & 6855 & $4960(72.4)$ & 51.5 & 40.9 & $10.6(8.7$ to 12.4$)$ & 1.26 (1.20 to 1.32$)$ \\
\hline \multicolumn{9}{|c|}{ Primary care provider visits } \\
\hline March & 137766 & $3528(2.6)$ & 4182 & $1840(44.0)$ & 30.4 & 27.5 & $2.9(1.6$ to 4.1$)$ & 1.11 (1.06 to 1.16$)$ \\
\hline April & 137467 & $3658(2.7)$ & 4714 & $3786(80.3)$ & 34.3 & 25.8 & 8.5 (7.2 to 9.6$)$ & 1.33 (1.27 to 1.39$)$ \\
\hline May & 137867 & 3517 (2.6) & 4484 & 3424 (76.4) & 32.5 & 27.4 & 5.1 (3.9 to 6.4$)$ & 1.19 (1.13 to 1.24$)$ \\
\hline June & 137707 & $3736(2.7)$ & 4691 & $3322(70.8)$ & 34.1 & 26.1 & $8.0(6.7$ to 9.1$)$ & 1.31 (1.25 to 1.37$)$ \\
\hline July & 138238 & $3723(2.7)$ & 4557 & 3066 (67.2) & 33.0 & 24.7 & 8.3 (7.2 to 9.4$)$ & 1.34 (1.28 to 1.40$)$ \\
\hline August & 137609 & $3471(2.5)$ & 4231 & $2781(65.5)$ & 30.7 & 25.8 & 4.9 (3.7 to 6.1$)$ & 1.19 (1.14 to 1.25$)$ \\
\hline September & 136820 & $3712(2.7)$ & 4524 & 2987 (65.2) & 33.1 & 25.9 & 7.1 (5.9 to 8.3 ) & 1.27 (1.22 to 1.33$)$ \\
\hline October† & 135377 & $3689(2.7)$ & 4496 & $2938(64.7)$ & 33.2 & 27.4 & $5.8(4.5$ to 7.0$)$ & 1.21 (1.16 to 1.27$)$ \\
\hline November† & 133241 & $3726(2.8)$ & 4537 & 2935 (63.9) & 34.1 & 26.9 & 7.1 (5.8 to 8.3 ) & 1.26 (1.21 to 1.32$)$ \\
\hline \multicolumn{9}{|c|}{ Psychiatrist visits } \\
\hline March & 137766 & $1352(1.0)$ & 1818 & 938 (51.6) & 13.2 & 13.0 & $0.2(-0.6$ to 1.0$)$ & 1.02 (0.96 to 1.08 ) \\
\hline April & 137467 & $1454(1.1)$ & 2259 & $2124(94.0)$ & 16.4 & 13.2 & $3.2(2.4$ to 4.0$)$ & 1.24 (1.17 to 1.32 ) \\
\hline May & 137867 & $1437(1.0)$ & 2132 & 2014 (94.5) & 15.5 & 13.9 & 1.5 (0.6 to 2.4 ) & 1.11 (1.04 to 1.18 ) \\
\hline June & 137707 & $1568(1.1)$ & 2343 & $2211(94.4)$ & 17.0 & 13.1 & 4.0 (3.1 to 4.8$)$ & 1.30 (1.22 to 1.39$)$ \\
\hline July & 138238 & $1555(1.1)$ & 2266 & 2034 (89.8) & 16.4 & 12.1 & 4.3 (3.5 to 5.0$)$ & 1.35 (1.27 to 1.44$)$ \\
\hline August & 137609 & $1434(1.0)$ & 1965 & 1761 (89.6) & 14.3 & 12.1 & 2.2 (1.4 to 2.9$)$ & 1.18 (1.11 to 1.26$)$ \\
\hline September & 136820 & $1529(1.1)$ & 2238 & 2021 (89.9) & 16.4 & 12.7 & 3.6 (2.8 to 4.4$)$ & 1.29 (1.21 to 1.37$)$ \\
\hline October $†$ & 135377 & $1500(1.1)$ & 2236 & $2031(90.2)$ & 16.5 & 13.4 & 3.1 (2.3 to 3.9$)$ & 1.23 (1.16 to 1.31$)$ \\
\hline November† & 133241 & $1484(1.1)$ & 2318 & 2095 (89.0) & 17.4 & 14.0 & 3.4 (2.5 to 4.2 ) & 1.24 (1.16 to 1.32 ) \\
\hline
\end{tabular}

Note: $\mathrm{Cl}=$ confidence interval.

*Expected visit rates were established from negative binomial regression models.

†For October and November 2020, not all births were yet reported to the Canadian Institutes for Health Information. Therefore, the data from those 2 months will not be generalizable to the whole province. 
over time to $63.9 \%$ in November. In contrast, the percentage of visits to psychiatrists that were virtual remained high from April onward (range 89.0\%-94.5\%).

In March 2020, the observed visit rate of 43.6/1000 was higher than the expected rate of $40.4 / 1000$ (Figure 1), with a rate difference of 3.1 visits/ 1000 women $(95 \% \mathrm{Cl} 1.2-4.9)$ and an IRR of 1.08 (95\% Cl 1.03-1.13) (Table 1). The increased visit rate was observed in primary care (Figure 2 and Table 1), and for anxiety disorders (Figure 3). The greatest overall increase in visit rate was in April (Figure 1), with a rate difference of 11.7 (95\% Cl 10.0-13.5) and an IRR of 1.30 (95\% Cl 1.24-1.36) (Table 1). Visits increased in primary and psychiatrist care, and for anxiety, depressive and substance use disorders (Table 1 and Figures 2 and 3). This pattern generally persisted through to November 2020; in some months, visit rates for bipolar and psychotic disorders were also slightly elevated.

In analyses stratified by time since delivery, increases in visit rates were more marked for individuals 0-90 days postpartum, especially from April through July 2020, than for those 91-365 days postpartum (Figure 4). Analyses stratified by maternal sociodemographic characteristics showed similar elevations by parity, but increases were smaller for postpartum people living in the lowest income quintile neighbourhoods relative to other quintiles (Appendix 2, Table S2, available at www.cmaj. ca/lookup/doi/10.1503/cmaj.210151/tab-related-content). Visit rates for people with Chinese surnames became elevated in April, with greater elevations over several months than other groups; rates for those with South Asian surnames became elevated starting only in June. We observed minimal variability by neighbourhood ethnic diversity quintile. After July, IRRs were lower in the northern than in the southern public health units (Appendix 2, Table S2 and Appendix 3, Table S3, available at www.cmaj.ca/lookup/doi/10.1503/cmaj.210151/tab-related-content).

\section{Discussion}

Over the first 9 months of the COVID-19 pandemic, clinical visits for postpartum mental illness were significantly more frequent than would have been expected from prepandemic patterns. Higher visit rates were seen in both primary and specialist care, most prominently for anxiety disorders, depressive disorders, and alcohol and substance use disorders, and early in the postpartum period. Postpartum people living in lower income neighbourhoods had far smaller increases in visit rates, and visits by people with South Asian surnames increased in frequency later in the pandemic compared with people of other ethnic backgrounds. We observed some regional variability, with relatively low increases in visits seen in northern public health units after July 2020.

Increased visit rates began in March 2020, although the state of emergency was declared only midway through the month, suggesting that distress related to the pandemic translated into an increased need for care very quickly. Whether the sustained elevation in service use is because of a true increase in mental health burden cannot be ascertained from these data. However,

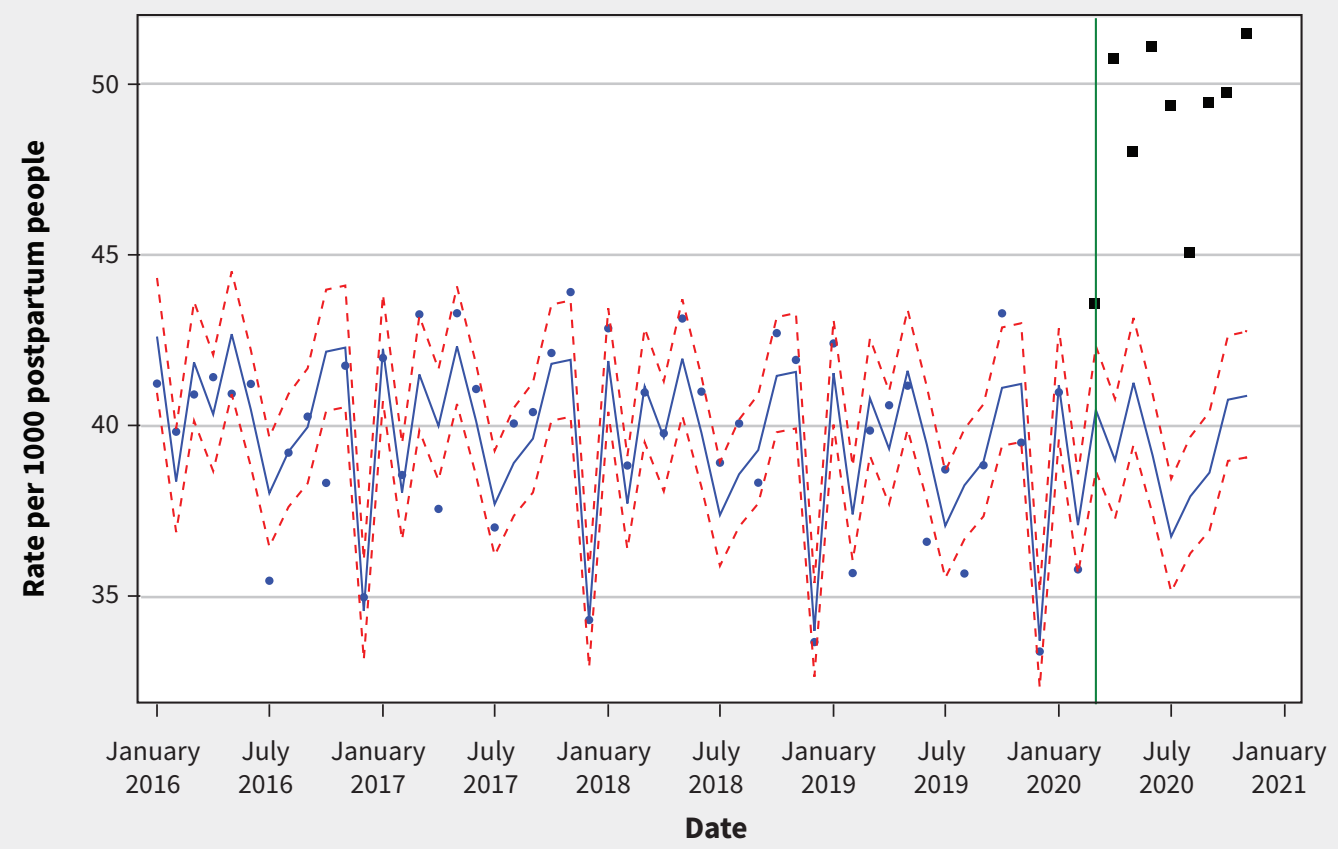

- Observed prepandemic - Observed during pandemic _ Expected _ - - Lower 95\% Cl - - - Upper 95\% Cl

Figure 1: Observed and expected rates of postpartum mental illness visits to primary care physicians or psychiatrists per 1000 postpartum people from January 2016 to November 2020, with 95\% confidence intervals (Cls). 
A

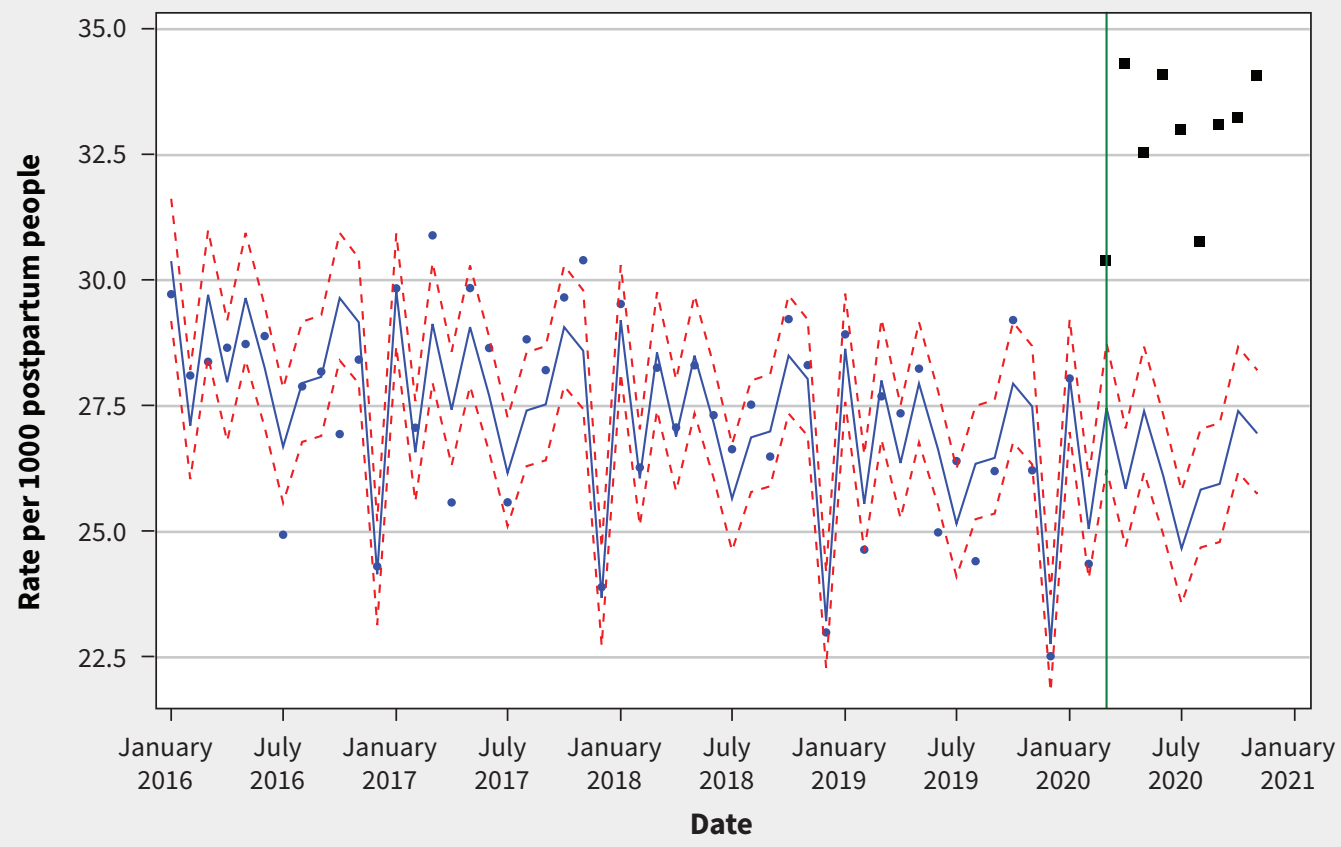

- Observed prepandemic @ Observed during pandemic — Expected - - - Lower 95\% Cl - - Upper 95\% Cl

B

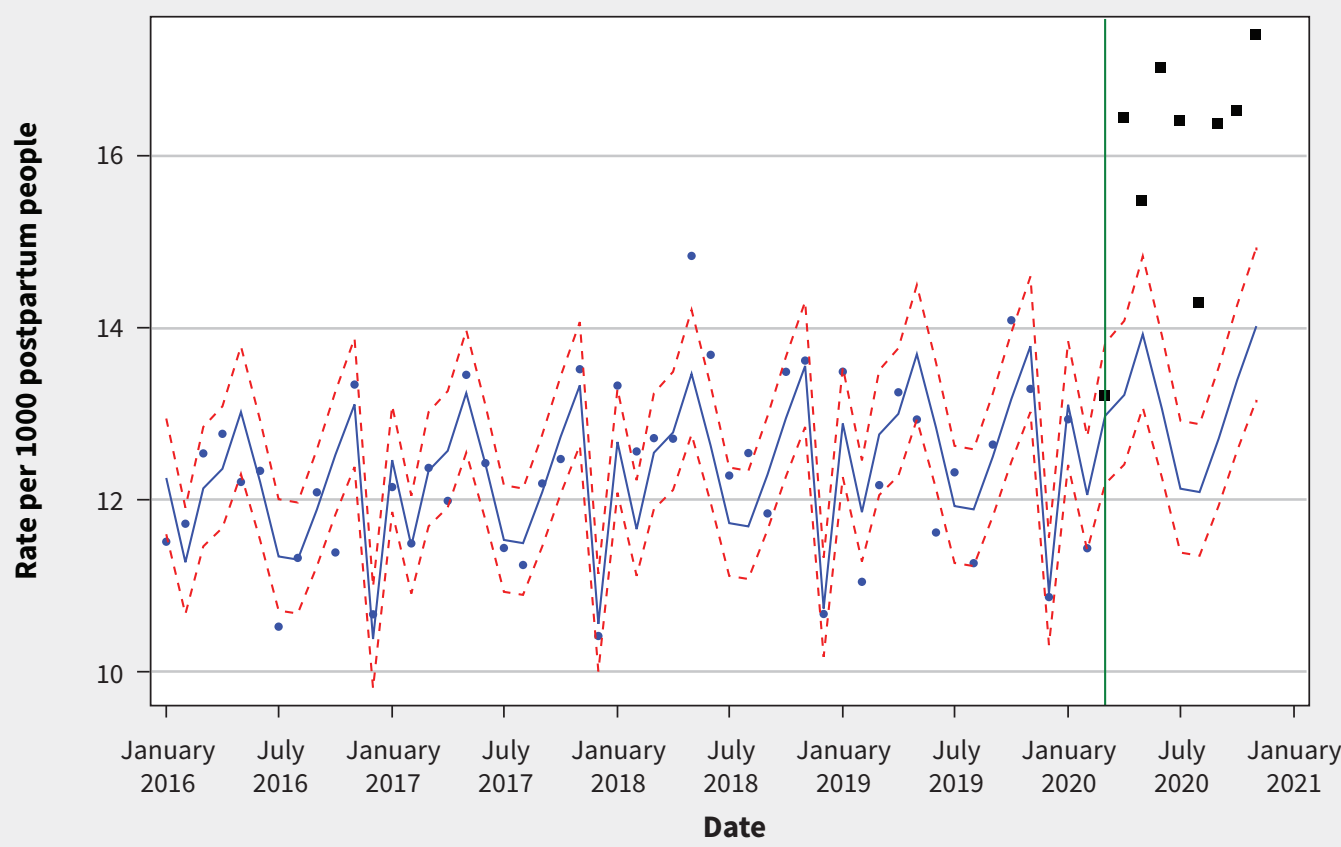

- Observed prepandemic - Observed during pandemic —_ Expected - - Lower $95 \% \mathrm{Cl} \quad$ - - - Upper $95 \% \mathrm{Cl}$

Figure 2: Observed and expected rates of postpartum mental illness visits per 1000 postpartum people to (A) primary care providers and (B) psychiatrists from January 2016 to November 2020, with 95\% confidence intervals (Cls). 
during the H1N1 pandemic, perinatal patients reported high anxiety, ${ }^{7}$ and similar concerns have arisen in the current pandemic. ${ }^{10}$ Increased accessibility of virtual care could also explain some of the observed trends. Virtual care may have alleviated common access barriers among postpartum patients, including logistical factors (e.g., unpredictable infant schedules, child care for older children, travel to appointments) and shame or stigma associated with seeking (or being seen seeking) mental health treatment. ${ }^{11,20,21}$

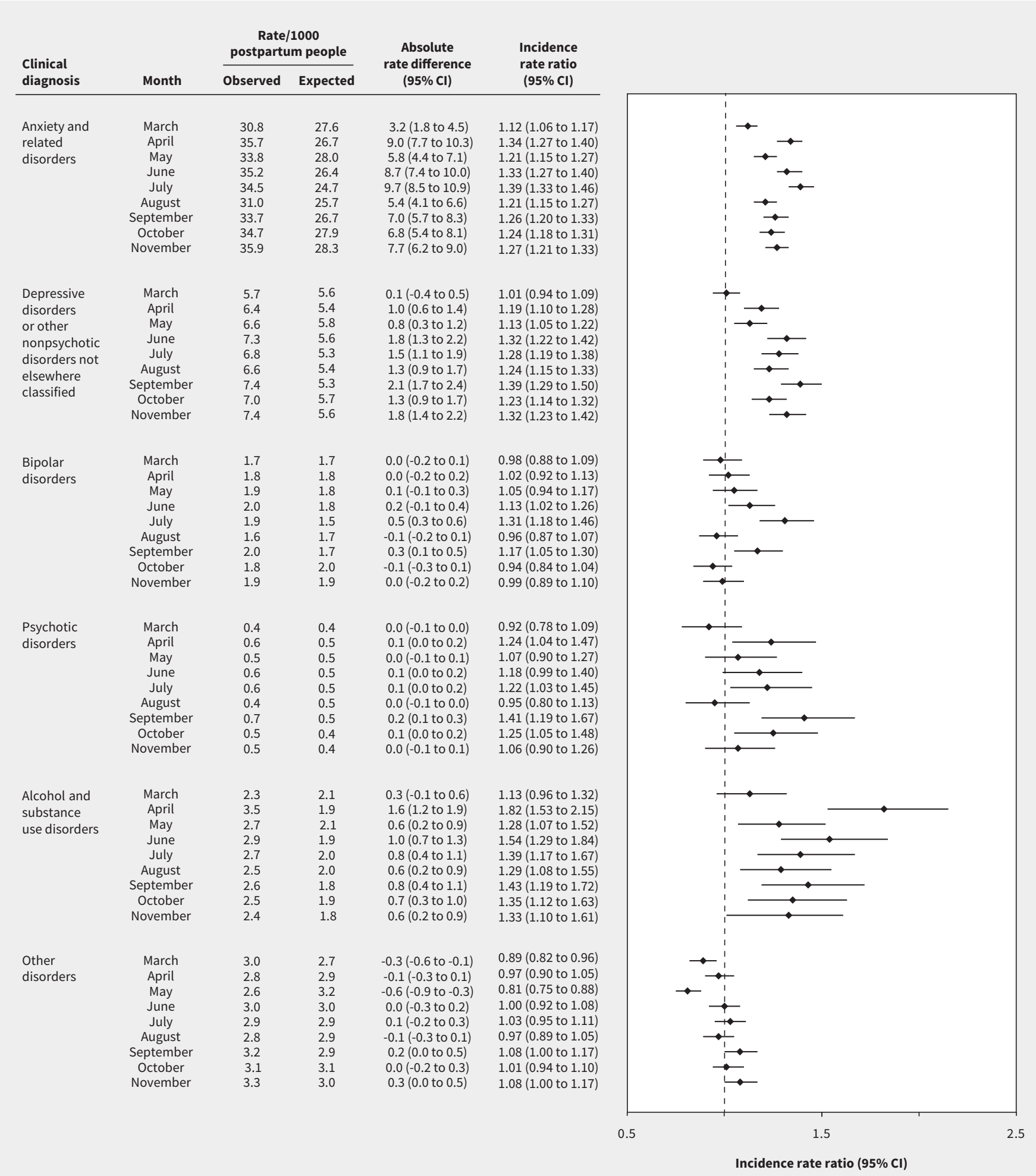

Figure 3: Rates, absolute rate differences and incidence rate ratios of postpartum mental illness visits to primary care physicians and psychiatrists per 1000 postpartum people from March to November 2020, comparing observed rates with expected rates as predicted by modelling from the prepandemic period (January 2016 to February 2020), by clinical diagnosis. Note: $\mathrm{Cl}=$ confidence interval. 
Many social determinants of health are linked to mental health and access to mental health care, including experiences of race or gender discrimination, socioeconomic status and geographic location. ${ }^{22}$ Interpersonal or family factors, community dynamics and social support are also important. ${ }^{22}$ Our findings suggest that the COVID-19 pandemic has had disproportionate effects on parents who have newly delivered, for whom support from extended networks is beneficial and may be limited with public health efforts to contain SARS-CoV- $2 .^{8}$

Although we expected to see the greatest increases in visit rates among low income patients, given that this population has been most heavily affected by COVID-19 and associated public health measures, patients in the lowest income group had the smallest increase in visit rates compared with other income quintiles. This raises some concern about the potential for unmet need because low income patients may have greater barriers to accessing care, including difficulty affording the required technology or finding private space to attend virtual appointments (e.g., crowded homes), or less opportunity to attend "live" appointments because of employment in front-line jobs. ${ }^{23}$ Furthermore, although the costs of physician services are covered by the province (even for nonresidents, during the pandemic), prescription medications and nonphysician psychotherapy services are not, which presents another potential barrier to help-seeking. The extent to which the variability across ethnic surname groups relates to differential effects of the pandemic on mental health, or to variability in patterns of access to and uptake of mental health care, warrants further exploration. ${ }^{24-26}$ Finally, although northern regions tend to have fewer specialized mental health resources available, ${ }^{27}$ visit rates were closer to expected levels only from August 2020 onward. These regions were subject to fewer COVID-19 restrictions after this time, when the province regionalized containment efforts, which may have reduced the burden of postpartum mental illness.

\section{Limitations}

Some will not seek care when experiencing poor mental health postpartum, and others will seek help outside the medical

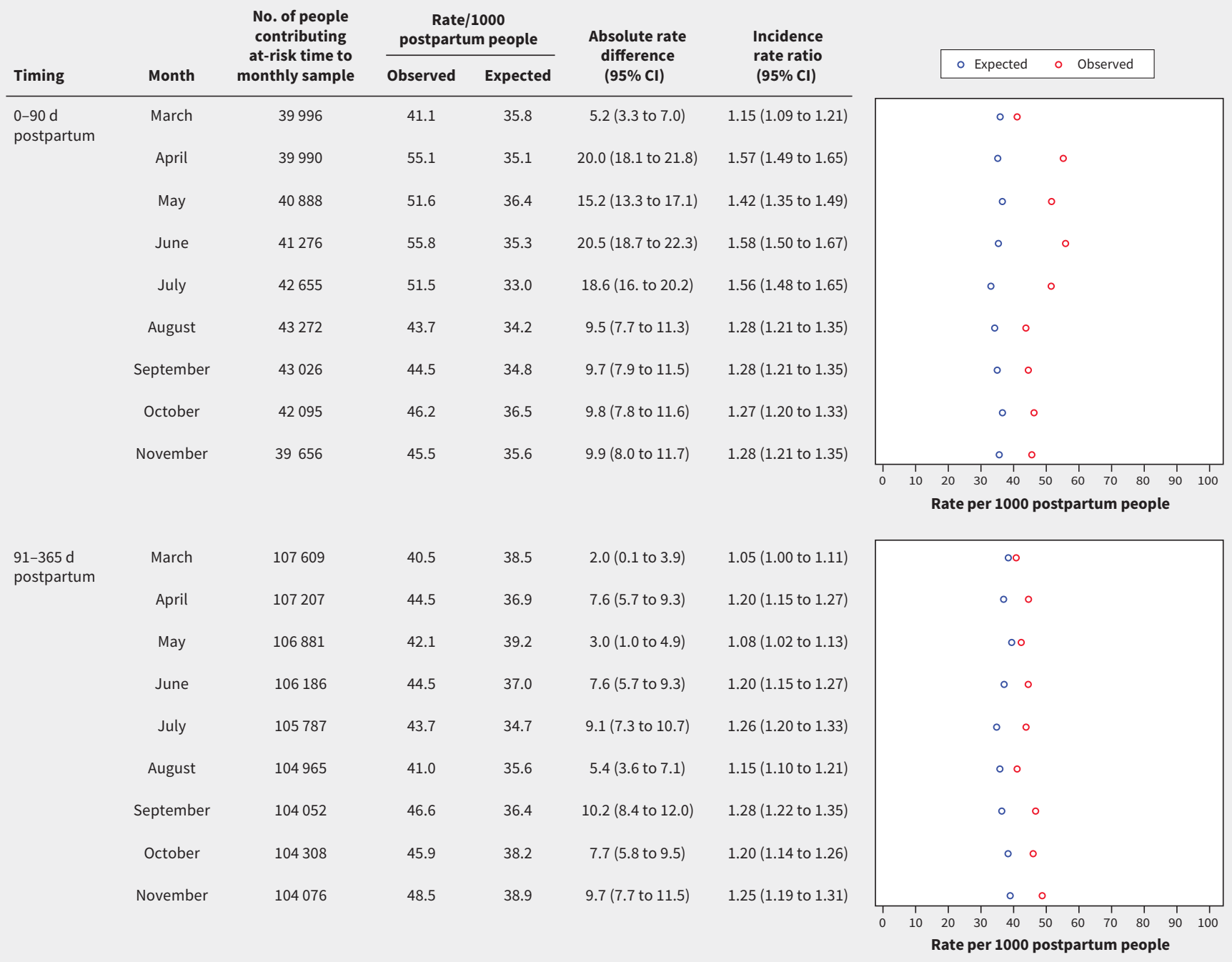

Figure 4: Rates, absolute rate differences and incidence rate ratios of visits to primary care physicians or psychiatrists for postpartum mental illness per 1000 postpartum people from March to November 2020, comparing observed rates with expected rates as predicted by modelling from the prepandemic period (January 2016 to February 2020), stratified by time since delivery (0-90 days postpartum and $91-365$ days postpartum). Note: $\mathrm{Cl}=$ confidence interval. 
system (e.g., peer support groups, private psychotherapists), so we may have undercaptured the clinical burden of illness. We did not evaluate comorbidities, so if a person had both depression and anxiety, only the primary diagnosis as assessed by the treating physician would be recorded. We also did not measure all types of service use for mental illness, such as emergency department visits and hospitalizations. Although utilization of acute care services for postpartum mental illness is generally low (in the range of 2 to 5 per 1000 births), ${ }^{28,29}$ if needs go unmet despite increased outpatient visit rates, higher acute care use could result over time. Future research should identify ongoing clinical burden as the pandemic progresses. Our measures of demographic characteristics were limited. We evaluated only neighbourhood-level, not individual-level, income. We captured only 2 ethnicities at the individual level, and for this we relied on a surname algorithm that has high specificity, but suboptimal sensitivity, especially for South Asian surnames. The results of this population-level study in Ontario, Canada, may not generalize to settings with different COVID-19 burden and containment efforts, or where health care services are organized differently.

\section{Conclusion}

We observed increased use of nonacute care services for postpartum mental health in Ontario during the first few months of the pandemic, suggesting that self-reported mental distress has translated into increased help-seeking for postpartum people. Health systems should focus proactively on patients from high-risk groups, monitor waiting lists for care, and explore creative solutions to expand system capacity, with special attention to postpartum patients who may be experiencing barriers to care. With the extensive use of virtual care in this population, further evidence regarding the safety and effectiveness of virtual treatment for postpartum mental illness should be sought.

\section{References}

1. Vigod SN, Stewart DE. Emergent research in the cause of mental illness in women across the lifespan. Curr Opin Psychiatry 2009;22:396-400.

2. Khalifeh $\mathrm{H}$, Hunt IM, Appleby L, et al. Suicide in perinatal and non-perinatal women in contact with psychiatric services: 15 year findings from a UK national inquiry. Lancet Psychiatry 2016;3:233-42.

3. Stein A, Pearson RM, Goodman SH, et al. Effects of perinatal mental disorders on the fetus and child. Lancet 2014;384:1800-19.

4. Woolhouse H, Gartland D, Mensah F, et al. Maternal depression from early pregnancy to 4 years postpartum in a prospective pregnancy cohort study: implications for primary health care. BJOG 2015;122:312-21.

5. lob E, Frank P, Steptoe A, et al. Levels of severity of depressive symptoms among at-risk groups in the UK during the COVID-19 pandemic. JAMA Netw Open 2020;3:e2026064.

6. Sümen A, Adibelli D. The effect of coronavirus (COVID-19) outbreak on the mental well-being and mental health of individuals. Perspect Psychiatr Care 2020 Oct. 26 [Epub ahead of print]. doi: 10.1111/ppc.12655.

7. Sasaki T-K, Yoshida A, Kotake K. Attitudes about the 2009 H1N1 influenza pandemic among pregnant Japanese women and the use of the Japanese municipality as a source of information. Southeast Asian J Trop Med Public Health 2013;44:388-99.
8. Howard LM, Molyneaux E, Dennis C-L, et al. Non-psychotic mental disorders in the perinatal period. Lancet 2014;384:1775-88.

9. Lebel C, MacKinnon A, Bagshawe M, et al. Elevated depression and anxiety among pregnant individuals during the COVID-19 pandemic. J Affect Disord 2020;277:5-13.

10. COVID19 pandemic adversely affecting mental health of women and people with children [news release]. Toronto: Centre for Addiction and Mental Health; 2020 Oct. 14. Available: www.camh.ca/en/camh-news-and-stories/covid-19 -pandemic-adversely-affecting-mental-health-of-women-and-people-with-children (accessed 2021 May 5).

11. Goodman JH. Women's attitudes, preferences, and perceived barriers to treatment for perinatal depression. Birth 2009;36:60-9.

12. Williams JI, Young W. A summary of studies on the quality of health care administrative databases in Canada. In: Goel V, Williams JI, Anderson GM, et al., editors. Patterns of Health Care in Ontario: The ICES Practice Atlas. Ottawa: Canadian Medical Association; 1996:339-45.

13. Nielsen K. A timeline of COVID-19 in Ontario. Global News 2020 Apr. 24. Available: https://globalnews.ca/news/6859636/ontario-coronavirus-timeline/ (accessed 2021 May 5).

14. Stewart DE, Vigod S. Postpartum depression. N Engl J Med 2016;375:2177-86.

15. Shah BR, Chiu M, Amin S, et al. Surname lists to identify South Asian and Chinese ethnicity from secondary data in Ontario, Canada: a validation study. BMC Med Res Methodol 2010;10:42.

16. Matheson FI, van Ingen T. 2016 Ontario marginalization index: user guide. Toronto: St. Michael's Hospital: 2018.

17. Table 6: Health regions reference maps. Ottawa: Statistics Canada; modified 2015 Nov. 27. Available: https://www150.statcan.gc.ca/n1/pub/82-402-x/2013003/ regions/hrt6-eng.htm (accessed 2021 May 5).

18. Steele LS, Glazier RH, Lin E, et al. Using administrative data to measure ambulatory mental health service provision in primary care. Med Care 2004;42:960-5.

19. Munk-Olsen T, Laursen TM, Pedersen CB, et al. New parents and mental disorders: a population-based register study. JAMA 2006;296:2582-9.

20. Byatt N, Levin LL, Ziedonis D, et al. Enhancing participation in depression care in outpatient perinatal care settings: a systematic review. Obstet Gynecol 2015;126: 1048-58.

21. Dennis C-L, Chung-Lee L. Postpartum depression help-seeking barriers and maternal treatment preferences: a qualitative systematic review. Birth 2006;33:323-31.

22. Alegría M, NeMoyer A, Falgas Bague I, et al. Social determinants of mental health: where we are and where we need to go. Curr Psychiatry Rep 2018;20:95.

23. López L, Green AR, Tan-McGrory A, et al. Bridging the digital divide in health care: the role of health information technology in addressing racial and ethnic disparities. Jt Comm J Qual Patient Saf 2011;37:437-45.

24. Zhao Y, Kane I, Wang J, et al. Combined use of the postpartum depression screening scale (PDSS) and Edinburgh postnatal depression scale (EPDS) to identify antenatal depression among Chinese pregnant women with obstetric complications. Psychiatry Res 2015;226:113-9.

25. Nilaweera I, Doran F, Fisher J. Prevalence, nature and determinants of postpartum mental health problems among women who have migrated from South Asian to high-income countries: a systematic review of the evidence. J Affect Disord 2014;166:213-26.

26. Ta Park VM, Goyal D, Suen J, et al. Chinese American women's experiences with postpartum depressive symptoms and mental health help-seeking behaviors. MCN Am J Matern Child Nurs 2019;44:144-9.

27. Kurdyak P, Stukel TA, Goldbloom D, et al. Universal coverage without universal access: a study of psychiatrist supply and practice patterns in Ontario. Open Med 2014;8:e87-99.

28. Polachek IS, Fung K, Vigod SN. First lifetime psychiatric admission in the postpartum period: A population-based comparison to women with prior psychiatric admission. Gen Hosp Psychiatry 2016;40:25-32.

29. Barker LC, Kurdyak P, Fung K, et al. Postpartum psychiatric emergency visits: a nested case-control study. Arch Womens Ment Health 2016;19:1019-27. 
Competing interests: Simone Vigod and Sophie Grigoriadis report royalties from UpToDate Inc for materials on perinatal depression. Elisabeth Wright reports grants from the Women's College Hospital Academic and Medical Services Group, and an honorarium for training as a provider for a clinical trial on perinatal psychotherapy. She is also a member of her hospital's Interim Equity Committee. Sophie Grigoriadis reports royalties from the Canadian Pharmacists Association, Norton, Myriad Neuroscience and Abbie for materials, consultations and presentations related to depression. No other competing interests were declared.

This article has been peer reviewed.

Affiliations: Women's College Research Institute (Vigod, Brown, Barker, Wright), Women's College Hospital; Department of Psychiatry (Vigod, Brown, Barker, Wright, Grigoriadis), Temerty Faculty of Medicine, University of Toronto; ICES Central (Vigod, Brown, Huang, Fung, Barker, Gozdyra, Moineddin); Institute for Health Policy, Management and Evaluation (Vigod, Brown, Barker, Hussain-Shamsy, Moineddin), Dalla Lana School of Public Health, University of Toronto; Department of Health and Society (Brown), University of Toronto Scarborough; Lawrence S. Bloomberg Faculty of Nursing (Dennis), University of Toronto; Sunnybrook Health Sciences Centre (Grigoriadis), Toronto, Ont.; Department of
Obstetrics and Gynecology (Corsi, Walker), University of Ottawa, Ottawa, Ont.; Department of Family \& Community Medicine (Moineddin), Faculty of Medicine, University of Toronto, Toronto, Ont.

Contributors: All authors conceptualized the study. Simone Vigod acquired the data, with input on design and analysis plans from Hilary Brown, Anjie Huang, Kinwah Fung and Rahim Moineddin. Anjie Huang conducted the analysis with input from Simone Vigod, Hilary Brown, Kinwah Fung and Rahim Moineddin. All authors interpreted the data. Simone Vigod drafted the manuscript, with all authors revising it critically for important intellectual content, and approving the final version to be published. Simone Vigod agrees to be accountable for all aspects of the work ensuring that questions related to the accuracy or integrity of any part of the work are appropriately investigated and resolved.

Content licence: This is an Open Access article distributed in accordance with the terms of the Creative Commons Attribution (CC BY-NC-ND 4.0) licence, which permits use, distribution and reproduction in any medium, provided that the original publication is properly cited, the use is noncommercial (i.e., research or educational use), and no modifications or adaptations are made. See: https://creativecommons. org/licenses/by-nc-nd/4.0/
Data sharing: The data set from this study is held securely in coded form at ICES. Although data sharing agreements prohibit ICES from making the data set publicly available, access may be granted to those who meet pre-specified criteria for confidential access, available at www. ices.on.ca/DAS. The full data set creation plan and underlying analytic code are available from the authors on request, understanding that the computer programs may rely upon coding templates or macros unique to ICES and are therefore inaccessible or may require modification.

Disclaimer: This study was supported by ICES, which is funded by an annual grant from the Ontario Ministry of Health $(\mathrm{MOH})$ and the Ontario Ministry of Long-Term Care (MLTC). The opinions, results and conclusions reported in this paper are those of the authors and are independent from the funding sources. No endorsement by ICES or the Ontario MOH or MLTC is intended or should be inferred. Parts of this material are based on data and/or information compiled and provided by $\mathrm{ClHI}$. However, the analyses, conclusions, opinions and statements expressed in the material are those of the author(s), and not necessarily those of $\mathrm{ClHI}$.

Accepted: May 5, 2021

Correspondence to: Simone Vigod, simone.vigod@wchospital.ca 